\title{
Permeation of sodium dodecyl sulfate through polyaniline-modified cellulose acetate membranes
}

\author{
A.J.M. Valente ${ }^{\mathrm{a}, *}$, H.D. Burrows ${ }^{\mathrm{a}}$, A.Ya. Polishchuk ${ }^{\mathrm{b}}$, C.P. Domingues ${ }^{\mathrm{a}}$, O.M.F. Borges ${ }^{\mathrm{c}}$, \\ M.E.S. Eusébio ${ }^{\text {a }}$, T.M.R. Maria ${ }^{\text {a }}$, V.M.M. Lobo ${ }^{\text {a }}$, A.P. Monkman ${ }^{\mathrm{d}}$ \\ ${ }^{a}$ Department of Chemistry, University of Coimbra, 3004-535 Coimbra, Portugal \\ ${ }^{\mathrm{b}}$ Kompamid LLC, 6 Proezd Zavoda 'Serp and Molot', Moscow 111250, Russian Federation \\ ${ }^{\mathrm{c}}$ Laboratory of Pharmaceutical Technology, Faculty of Pharmacy, Coimbra University Rua do Norte, 3000 Coimbra, Portugal \\ ${ }^{\mathrm{d}}$ Department of Physics, Organic Electroactive Materials Research Group, University of Durham, Durham DH1 $3 L E$, UK
}

Received 19 April 2004; received in revised form 18 November 2004; accepted 17 May 2005

Available online 13 June 2005

\begin{abstract}
The preparation of polyaniline (PANi)-cellulose acetate (CA) blends by casting films from a suspension, is reported. Two membranes were prepared from different solvents, one with a homogeneous and the other a heterogeneous dispersion of PANi in CA matrices. The membranes were characterized by X-ray diffraction, SEM, DSC, and FTIR, and the results were compared with those obtained for pure CA and PANi films. The transport properties of water and sodium dodecyl sulfate (SDS) in membranes of the PANi-CA blends and of CA were analysed. The transport of SDS and water depends on both the bulk/polymer density and the PANi content. In the homogeneous blend, the interaction between SDS and the polymer plays an important role in the transport mechanism. An irreversible interaction is observed, which can be monitored by UV-vis spectroscopy. The spectra of homogeneous, highly transparent PANi-CA blends show a pronounced sensitivity to SDS concentration, with detection limits $[\mathrm{SDS}] \geq 0.1 \mathrm{mM}$ for films with a PANi concentration of $0.05 \% \mathrm{w} / \mathrm{v}$.
\end{abstract}

(C) 2005 Elsevier Ltd. All rights reserved.

Keywords: Cellulose acetate; Polyaniline; Sodium dodecyl sulfate

\section{Introduction}

Conducting polyaniline (PANi) has been widely investigated due to its potential for applications in electronic devices $[1,2]$. However, the applications are hampered by the relatively poor mechanical properties of the polymer, and much work has been done to develop different matrixes modified with PANi. Cellulose derivatives can be used as good polymeric supports for PANi, with the conduction in blends of cellulose derivatives depending on the amount of PANi, synthesis process, and additives [3,4]. A number of applications of cellulose acetate-PANi blends have been reported in the literature, including electronic devices $[5,6]$, selective electrodes [7] and as supports for urease

\footnotetext{
* Corresponding author. Tel.: +351 239854459; fax: +351 239827703.

E-mail address: avalente@ci.uc.pt (A.J.M. Valente).
}

0032-3861/\$ - see front matter (C) 2005 Elsevier Ltd. All rights reserved. doi:10.1016/j.polymer.2005.05.103 immobilization for biochemical applications [8]. Most of the reported work has been carried out in the last 10 years, and nothing has been reported on ionic permeation of different solutes in these types of blends. We are particularly interested in application of blends containing PANi with cellulose esters [4], as hole transport layers for electronic devices, such as multilayer polymeric and organic light emitting diodes (LEDs) [9,10]. These multicomponent systems frequently suffer the limitation of polymer incompatibility, leading to phase separation of the various components. However, interesting aggregation behaviour can be observed with polymer membranes and surfactants, which may be affected by such phase separation. We are, therefore, interested in the transport of surfactants within membranes of PANi containing polymer blends of differing degrees of heterogeneity. We have chosen blends involving cellulose derivatives, and report the polymeric preparation and characterization of two different cellulose acetate-based polyaniline blends and the effect of transport of the anionic surfactant SDS on those polymers. 


\section{Experimental procedure}

\subsection{Reagents}

High purity polyaniline in powder form as its emeraldine form was prepared by chemical polymerisation [11]. Cellulose acetate, CA, was purchased from Aldrich-Spain, with a weight-average molecular weight of 30,000 and with $39.8 \mathrm{wt} \%$ acetyl groups. Solutions of sodium dodecyl sulfate, Merck-pro analysis, $(0.1 \mathrm{mM}$ to $0.1 \mathrm{M})$ were prepared using bi-distilled water. Tetrahydrofuran and methanoic acid (formic acid, $\mathrm{HCOOH}$, Aldrich) were used as received.

\subsection{Membranes}

The polymeric films were prepared by initially dissolving cellulose acetate (CA) and/or polyaniline (PANi) in either tetrahydrofuran (THF) or a THF/HCOOH mixture, at the concentrations shown in Table 1, and stirring for $24 \mathrm{~h}$. For mixtures P1 and P3, homogeneous solutions were obtained, while with P2 a heterogeneous dispersion was observed. Films were deposited from these mixtures on flat glass supports by solvent evaporation using a Simex automatic film applicator. Specific moulds were used to prepare membranes with a homogeneous thickness. With membranes of P1 and P2, evaporation was at room temperature, whilst with P3 this was made with the help of infrared lamp. During this process the colour of this polymer changed from green to deep blue, probably as a consequence of methanoic acid evaporation and consequent PANi-deprotonation. After complete evaporation of solvent, membranes were removed from the glass support with the help of water.

The preparation of membrane P3 will be described in more detail as a typical example. Cellulose acetate (ca. $3 \mathrm{~g}$ ) was dissolved in THF $(15 \mathrm{~mL})$; a solution of polyaniline $(0.0105 \mathrm{~g})$ in $5 \mathrm{~mL}$ of methanoic acid $(5 \mathrm{~mL})$ was also prepared. The solutions were then mixed and left to homogenize for at least $24 \mathrm{~h}$ with stirring.

The polymers P1 and P3 show macroscopically homogeneous membranes, whilst $\mathrm{P} 2$ show a random dispersion of PANi throughout the film. A membrane of pure polyaniline was prepared by dip coating.

\subsection{Polymer characterization}

Membranes were characterised by their infrared spectra

Table 1

Chemical composition of solutions used for the polymeric membranes

\begin{tabular}{llll}
\hline Polymer & CA $(\% \mathrm{w} / \mathrm{v})$ & PANi $(\% \mathrm{w} / \mathrm{v})$ & Solvent \\
\hline P1 & 15 & 0 & THF \\
P2 & 15 & 0.3 & THF \\
P3 & 15 & 0.05 & THF:HCOOH, \\
& & & $3: 1$ \\
\hline
\end{tabular}

using a ATI Mattson Genesis Series FTIR spectrometer Polymer samples (ca. $10 \mu \mathrm{m}$ thickness) were cut from a membrane and dried at $60{ }^{\circ} \mathrm{C}$ during several days, before recording spectra.

The morphologies of the polymer films were analysed using a Jeol/Scanning Microscope, model 5310 under low vacuum, and at $20 \mathrm{kV}$.

The degree of crystalinity of the polymeric films were evaluated using a Philips, model X-Pert X-ray diffractometer operating at $40 \mathrm{kV}$, using Co as radiation source and a graphite filter. The scans were obtained using a scan step size of $0.025^{\circ}$ with a scan step time of 0.5 .

Differential scanning calorimetry measurements were carried out in a power compensation DSC7 Perkin-Elmer instrument, equipped with a CCA7 cooling unit. Scans were performed between 0 and $450{ }^{\circ} \mathrm{C}$ with a scan rate of $25^{\circ} \mathrm{C} / \mathrm{min}$. Sample weights of about $6 \mathrm{mg}$ were use in $50 \mu \mathrm{L}$ aluminium pans with holes. An empty pan was used as the reference. Temperature calibration was made with cyclohexane $\left(T_{\text {fus }}=6.7^{\circ} \mathrm{C}\right)[12]$, indium $\left(T_{\text {fus }}=156.6^{\circ} \mathrm{C}\right)$ [12], and zinc $\left(T_{\text {fus }}=419.5^{\circ} \mathrm{C}\right)$ [12]. In all measurements dry nitrogen $(20 \mathrm{~mL} / \mathrm{min})$ was used as the purge gas. The density of the dry polymeric films was determined by weighing a section of know area, at $25^{\circ} \mathrm{C}$.

\subsection{Percentage of water uptake}

Various samples of each membrane were cut, immersed in water, and were left in equilibrium in this medium until the sample weight reached an equilibrium value $M_{\mathrm{eq}}$. Subsequently, the membranes were dried in a vacuum oven at $100{ }^{\circ} \mathrm{C}$ until constant weight, $M_{0}$. The weight/weight $(\mathrm{w} / \mathrm{w})$ water concentration in the membrane, $C_{\mathrm{w}}$, was calculated from

$C_{\mathrm{w}}=\frac{M_{\mathrm{eq}}-M_{0}}{M_{\mathrm{eq}}}$

All gravimetric measurements on water sorption were made (to $\pm 0.1 \mathrm{mg}$ ) using an ADA 120LE balance.

\subsection{Water permeation}

The diffusion coefficients of water in the different polymer membranes were measured using a previously described technique [13]. This uses a cell with two compartments, A, completely filled with distilled water and $\mathrm{B}$, with poly(ethylene glycol), with a membrane $1.950 \mathrm{~cm}$ diameter separating them. The variation of water volume during the diffusion studies is measured by a capillary positioned in the upper side of the cell. The poly(ethylene glycol) (molecular weight 400, Fluka, purum) in compartment B is continuously stirred to maintain the concentration of water in the bottom of the membrane equal to zero.

All the membranes were immersed in water $24 \mathrm{~h}$ before 
the beginning of the experiment in order to attain equilibrium rapidly.

The water diffusion coefficients were determined using an adaptation of Fick's first law equation:

$\rho_{0} \frac{\mathrm{d} h}{\mathrm{~d} t}=C_{\mathrm{w}} D_{\mathrm{w}}\left(\frac{s_{\mathrm{m}}}{a_{\mathrm{c}}}\right) l^{-1}$

where $\rho_{0}$ is the water density, $\mathrm{d} h / \mathrm{d} t$ is the variation of the height of column of water in the capillary tube with time, $C_{\mathrm{w}}$ is the weight/weight water concentration in the membrane surface in contact with water phase, $s_{\mathrm{m}}$ is the area of membrane surface and $a_{\mathrm{c}}$ is the capillary area.

\subsection{Fluorescence measurements}

Fluorescence measurements on membranes were made using a Spex Fluorolog 111 spectrometer, with samples mounted in $1 \mathrm{~cm}^{2}$ quartz cuvettes and excitation at $337 \mathrm{~nm}$. A sample of each polymer blend was immersed in an aqueous solution of pyrene (Py, $\left.10^{-5} \mathrm{M}\right)$ in SDS (10 mM) overnight, removed and then its fluorescence spectrum measured. Fluorescence was also used to study diffusion of SDS across the membranes by measuring the spectra of aliquots of solution from cell $\mathrm{B}$ in $1 \mathrm{~cm}^{2}$ quartz cuvettes.

\subsection{UV-vis measurements}

UV-spectra were obtained using a Jasco V-530 spectrophotometer; the spectra were obtained directly inserting the polymer sample on the spectrophotometer, and using wavelength range between 800 and $200 \mathrm{~nm}$, with a bandwidth of $1.0 \mathrm{~nm}$.

\subsection{Permeation experiments}

Permeability of sodium dodecyl sulfate was measured using a previously reported cell [14]. This consists of two $250 \mathrm{~mL}$ cells filled with surfactant solution (A) and water (B), respectively. These were connected by two $7 \mathrm{~mm}$ radius horizontal tubes, with the polymer membrane sealed, with silicone, between these two tubes. The membranes were immersed in water for at least 3 days prior to experiments. Control experiments were made to ensure that there is no silicone in the permeation area, and that mass transport only occurs at the polymer-solution interface. To prevent any contribution from the hydrostatic pressure to the mass flux, cell A was filled with $200 \mathrm{~mL}$ of SDS solution, and the other cell with $200 \mathrm{~mL}$ of water. The change in the ionic solute concentration in cell B was determined during the permeability experiment by measuring the electrical conductivity using a YSI 3200 instrument. This was calibrated prior to each experiment using at least five freshly prepared standard solutions of the surfactant, with different concentrations. The same conditions were used for calibration and permeability experiments. Constant temperature $\left( \pm 0.1^{\circ} \mathrm{C}\right)$ was maintained by immersing the system in a thermostat bath (Velp Sientifica Multistirrer 6). Solutions in both cells were stirred at ca. $200 \mathrm{rpm}$ to decrease the Nernst layer in the membrane-solution interface and to increase the reproducibility of the conductivity sensor.

The permeability of ionic solutes through the polymeric membranes can be described in terms of Fickian diffusion

$\frac{\partial C}{\partial t}=\frac{\partial}{\partial x}\left(D_{\mathrm{F}} \frac{\partial C}{\partial x}\right)$

with the boundary and initial conditions $C(0, t)=C, C(l, t)=$ 0 , (where $C$ is the ionic concentration in the membrane) and $C(x, 0)=0$, resulting in the simple formulae for calculation of the permeability $(P)$ and diffusion coefficient $\left(D_{\mathrm{F}}\right)$

$P=\frac{J l}{c}$

$D_{\mathrm{F}}=\frac{l^{2}}{6 \theta}$

where $l$ is the thickness of polymeric membrane, measured after each experiment at $25^{\circ} \mathrm{C}$ using a Helias micrometer $( \pm 0.001 \mathrm{~mm}), J$ is a steady-state flux through the membrane, $\theta$ is the time-lag, and $c$ is the bulk surfactant concentration.

In SDS permeability experiments, at concentrations above the critical micellar concentration $(\mathrm{cmc})$, as in the present study, the diffusion of surfactant is complicated by the aggregation equilibrium between single surfactant molecules and micelles. In this case, the flux of surfactant through a polymer membrane depends on the concentrations of counter-ions, monomers, and micelles [15,16]. However, the formation and break-up of micelles are much faster processes than surfactant diffusion, and this can be considered in terms of the dominant species [15]. Since, at concentrations above the cmc, the concentration of surfactant present as micelles is usually higher than that of free monomer, the diffusion of surfactants would be expected to be micelle controlled [17]. However, studies using the fluorescence of pyrene as probe in SDS have shown that this is not the case, and that whole micelles cannot cross through membranes. This means that as long as the SDS concentration in cell $\mathrm{A}$ is above the $\mathrm{cmc}$, the monomer concentration on this side of the polymer membrane remains constant $\left(C(0, t)=[\mathrm{SDS}]_{\mathrm{cmc}}\right)$ due to the monomer/micelle equilibrium. Therefore, Eq. (4) can be rewritten as

$P=\frac{J l}{[\mathrm{SDS}]_{\mathrm{cmc}}}$

The cmc for SDS used in Eq. (6), were $8.3 \times 10^{-3}$ mol dm ${ }^{-3}$ [18].

The validity of Eqs. (3)-(6) to the SDS-polymer systems is a consequence of the experimental data (ionic 
conductivity as a function of time) used to calculate $D_{\mathrm{F}}$ and $P$, being obtained under steady-state conditions. The steadystate fluxes are reached 3-4 days (CA membranes) and 5-7 days (PANi blends) after the beginning of experiments with SDS.

\section{Results and discussion}

\subsection{Structural properties of the polymers}

The FTIR spectra were run of membranes of polymers P1, P2 and P3 (Fig. 1).

In addition to absorptions of cellulose acetate (1748, 1234 and $1046 \mathrm{~cm}^{-1}$ ), new bands were observed in films of P2 and P3; in particular at around 1740, 1295, and $1244 \mathrm{~cm}^{-1}$. From comparison with IR spectra reported in literature [19,20], these are consistent with incorporation of PANi in the blends as its emeraldine base. In addition, certain differences and collapse were observed in relative band intensities as well as the shift of some bands between the homogeneous membrane P3 and the heterogeneous P2 (see for example peak at $1724 \mathrm{~cm}^{-1}$ ). These are most probably associated with the differences in polymer morphology and miscibility degree (see DCS thermograms below). The absence of peaks at around $1500 \mathrm{~cm}^{-1}$, characterizing the aromatic ring of the aniline, can be due to the very low concentration of PANi used in the blends P2 and P3. Therefore, it is only possible to observe the effect of PANi in the CA structure.

In Fig. 2(1) a typical thermogram is presented for heating cellulose acetate between 25 and $290^{\circ} \mathrm{C}$. Of particular note is an endothermic peak (temperature maximum, $T_{\max }=$ $91{ }^{\circ} \mathrm{C}$ ), probably due to the loss of moisture adsorbed in the membrane. Heating until $150{ }^{\circ} \mathrm{C}$ led to a weight loss of about $4 \%(\mathrm{w} / \mathrm{w})$. A glass transition was also observed $\left(T_{\mathrm{g}}=\right.$ $197^{\circ} \mathrm{C}$ ). These results are consistent with those obtained by Wang et al. [21] on similar CA membranes prepared from acetone. Following the glass transition we observe a small endothermic peak $\left(T_{\max }=220^{\circ} \mathrm{C}\right)$, that may indicate some degree of order in the membrane. In second heating runs, performed after cooling the sample from 290 to $0{ }^{\circ} \mathrm{C}$, only the second order transition was normally observed with $T_{\mathrm{g}}=185^{\circ} \mathrm{C}$ (Fig. 2(2)). In some experiments the endothermic peak following this transition was also observed, although its intensity was reduced relatively to first heating runs.

A thermogram obtained on heating a CA sample previously scanned to $150{ }^{\circ} \mathrm{C}$ and afterwards cooled to $0{ }^{\circ} \mathrm{C}$ is shown in Fig. 2(3). In this experiment, the temperature was raised in order to determine the stability limit of CA. Degradation is obvious at $325^{\circ} \mathrm{C}$ and, therefore, in all subsequent experiments $290{ }^{\circ} \mathrm{C}$ was set as the temperature limit.

PANi films seem also to loose adsorbed moisture, with this process being followed by a set of transitions giving rise to a weight loss of about $20 \%$ (w/w) until $290{ }^{\circ} \mathrm{C}$ (Fig. 2(6)), which may be due to some degradation [22,23].

The thermograms presented in Fig. 2(4) and (5) corresponding to first and second runs performed on P3 blend show the same features observed in CA membranes. However, the glass transition in the first run is shifted to higher temperature $T_{\mathrm{g}}=209^{\circ} \mathrm{C}$, and the same happens with the temperature of the maximum of the endothermic transition, $T_{\max }=238^{\circ} \mathrm{C}$. This transition is also more energetic in the blends.

The behaviour of $\mathrm{P} 2$ blend is not dissimilar from that of cellulose acetate.

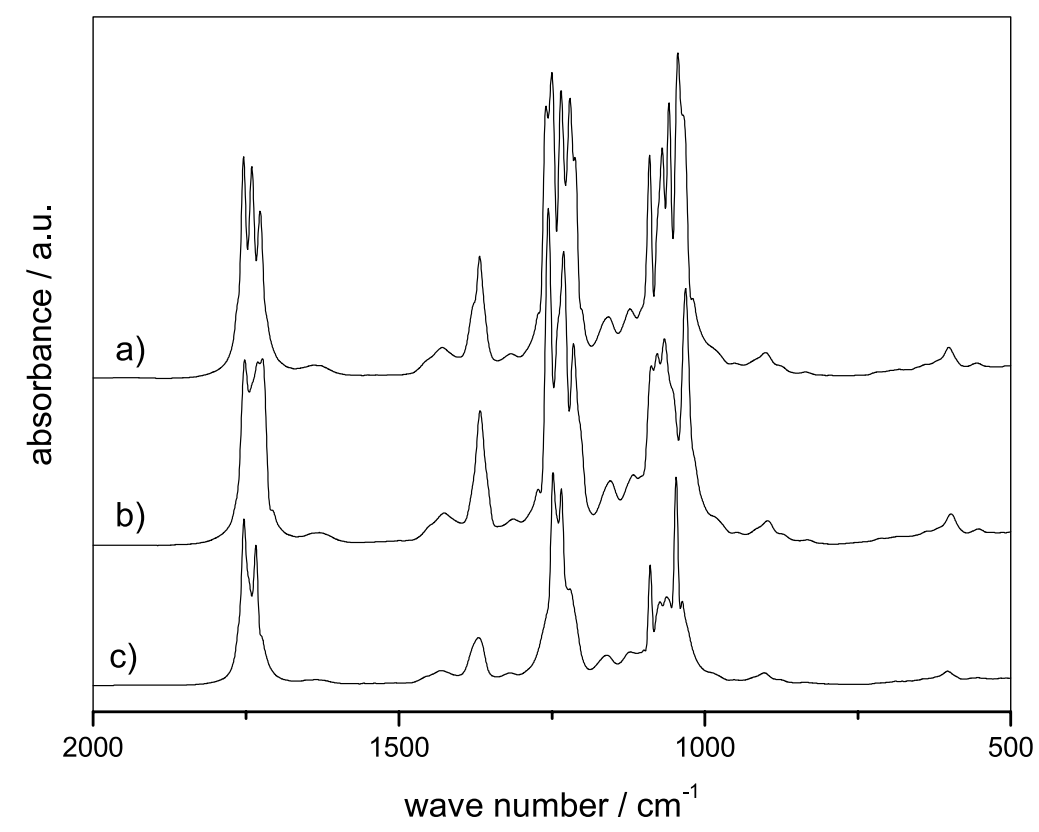

Fig. 1. Infrared spectra of cellulose acetate-polyaniline blends; (a) P1, (b) P2, (c) P3. 


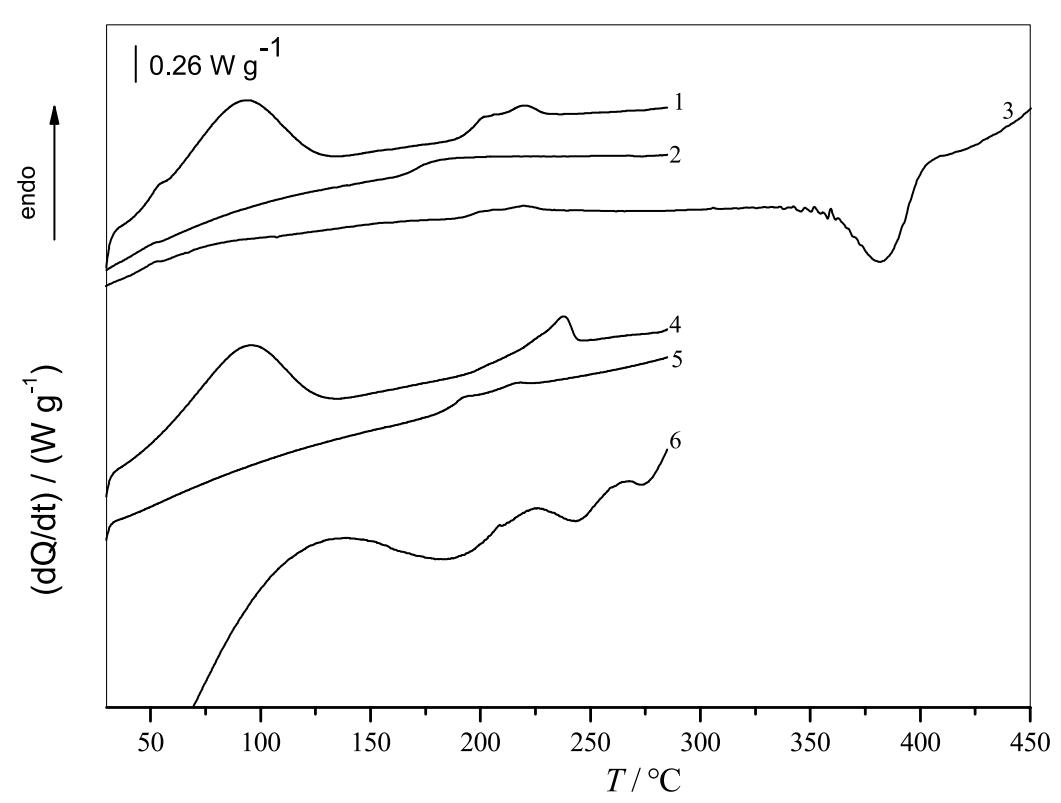

Fig. 2. DSC curves for heating runs performed on (1)-(3) P1, (4) and (5) $\mathrm{P} 3$ and (6) PANi, at $25^{\circ} \mathrm{C} / \mathrm{min}$. For further details see text.

Confirmation of modifications in the polymeric structure in PANi-modified cellulose-acetate membranes also came from SEM and X-ray diffraction studies.

Fig. 3 shows the micrographs of the different polymer films with an amplification of $\times 3500$. As previously reported for cellulose acetate [24], the CA film shows a very porous surface. With the incorporation of PANi in cellulose acetate blends the surface morphology changes. The blend P2 had a rather smooth and featureless surface, showing a predominant effect of PANi in the surface morphology [25]. Different particles can also be found (Fig. 3(b)), showing two different phases and different particle PANi sizes. The more homogeneous blend P3 of PANi and CA (micrograph in Fig. 3(c)) also shows a clear modification of the surface morphology, with a relatively homogeneous surface but with some roughness, which is different from the other polymers including PANi (Fig. 3(d)). Looking at the cross-section of the film P3 (Fig. 4), as has previously been reported for these blends [26], the arrangement of PANi is anisotropic, with a preferential orientation in the plane of the film. In this film, the anisotropy only partially disappears, showing that the matrix core of the P3 structure is still dependent on PANi.

Further information on the structural properties of the polymer films was obtained by X-ray diffraction (Fig. 5). With the blends P2 and P3, the broad maxima are very close to those of the first maximum in the PANi film. In addition, with $\mathrm{P} 3$ a shoulder is observed close to the second maximum in PANi. In these relatively amorphous samples, the X-ray diffraction patters are dominated by local structure, and although, as seen by visual inspection, P3 is homogeneous at the macroscopic level, the PANi must maintain some of its local structure, as suggested by the SEM measurements.

\subsection{Physical properties of the polymers}

Table 2 shows the effect of the PANi addition to cellulose acetate membrane on the weight/weight (\%) water concentration, water diffusion coefficient and polymer density.

The incorporation of polyaniline in cellulose acetate matrices is accompanied by a decrease of water sorption and a decrease of water diffusion coefficient. Although the water diffusion coefficients depends on various factors, including mechanical, surface and matrix properties [27], the incorporation of $\mathrm{PANi}$, in the present case, accompanied by an increase of the polymer hidrophobicity, is the main factor affecting the water transport.

\subsection{Transport of sodium dodecyl sulfate}

Fig. 6 shows the permeability and diffusion coefficients of SDS in pure cellulose acetate membranes (polymer P1). There is an increase of $P$ and a decrease of $D$ with an increase of SDS concentration in the pre-micellar region. The magnitude of the permeability coefficients is similar to those obtained in membranes of other cellulose esters [28] and the diffusion coefficients, obtained in steady-state conditions, are five orders of magnitude lower than for

Table 2

Diffusion coefficients of water in modified-PANi cellulose acetate membranes

\begin{tabular}{lllll}
\hline Polymer & $l(\mathrm{~mm})$ & $\begin{array}{l}C_{\mathrm{w}}( \pm s) \\
(\mathrm{g} \mathrm{g})\end{array}$ & $\begin{array}{l}D_{\mathrm{w}}( \pm s) \\
\left(10^{-13} \mathrm{~m}^{2} \mathrm{~s}^{-1}\right)\end{array}$ & $\begin{array}{l}d_{\mathrm{P}}( \pm s) \\
\left(\mathrm{g} \mathrm{cm}^{-3}\right)\end{array}$ \\
\hline P1 & 0.030 & $0.51( \pm 0.05)$ & $45.3( \pm 2.2)$ & $0.91( \pm 0.11)$ \\
P2 & 0.050 & $0.15( \pm 0.04)$ & $0.86( \pm 0.08)$ & $0.30( \pm 0.05)$ \\
P3 & 0.042 & $0.22( \pm 0.03)$ & $0.24( \pm 0.03)$ & $0.65( \pm 0.09)$ \\
\hline
\end{tabular}




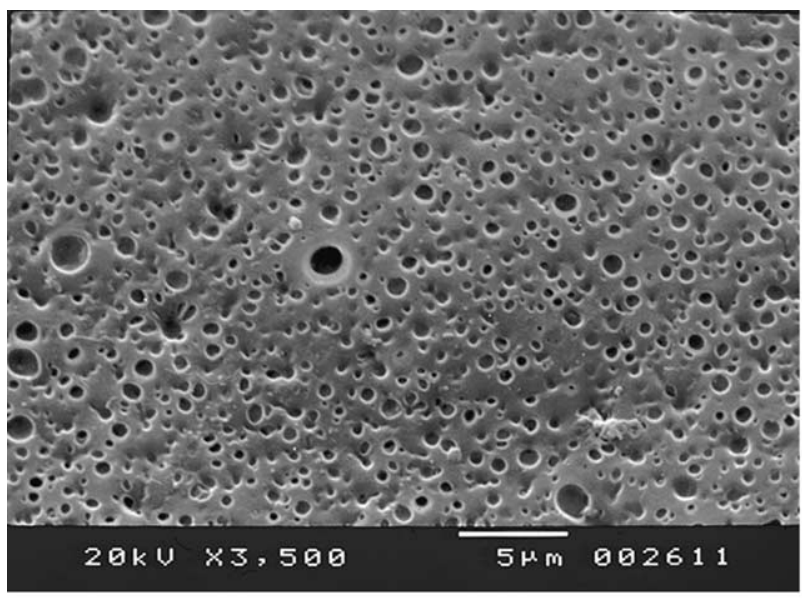

(a)

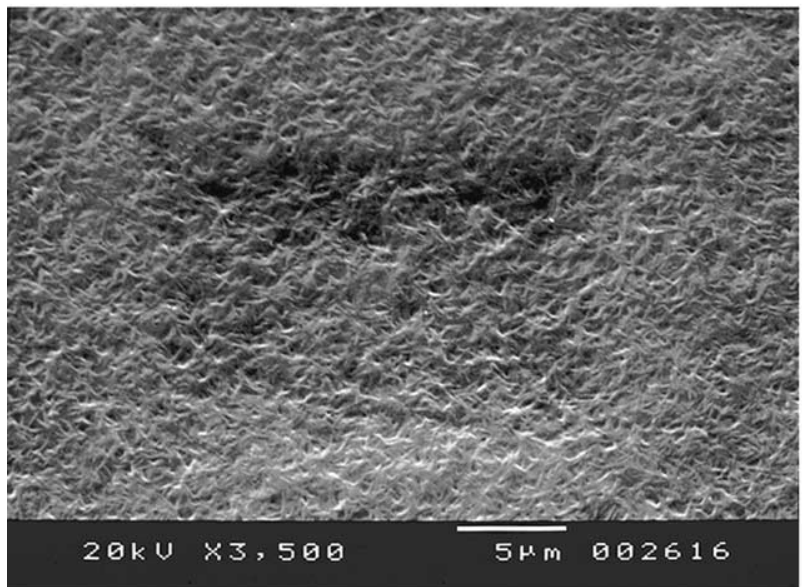

(c)

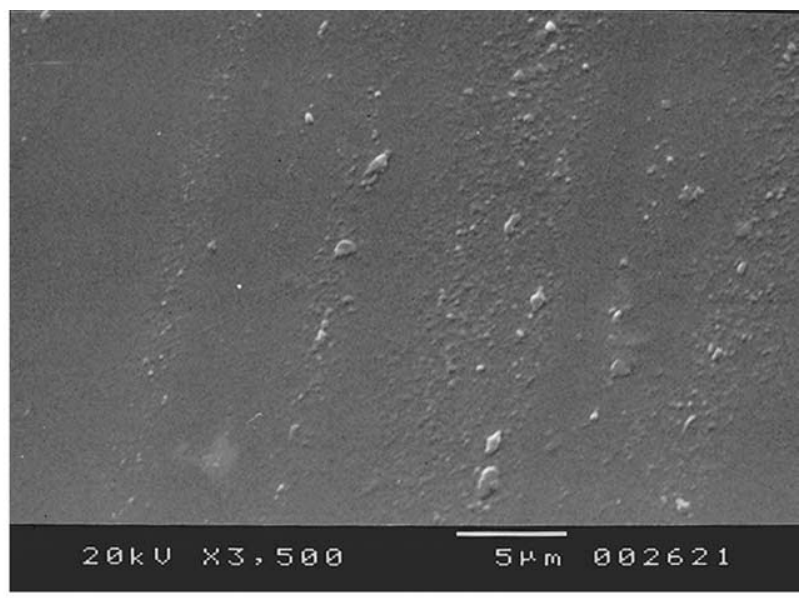

(b)

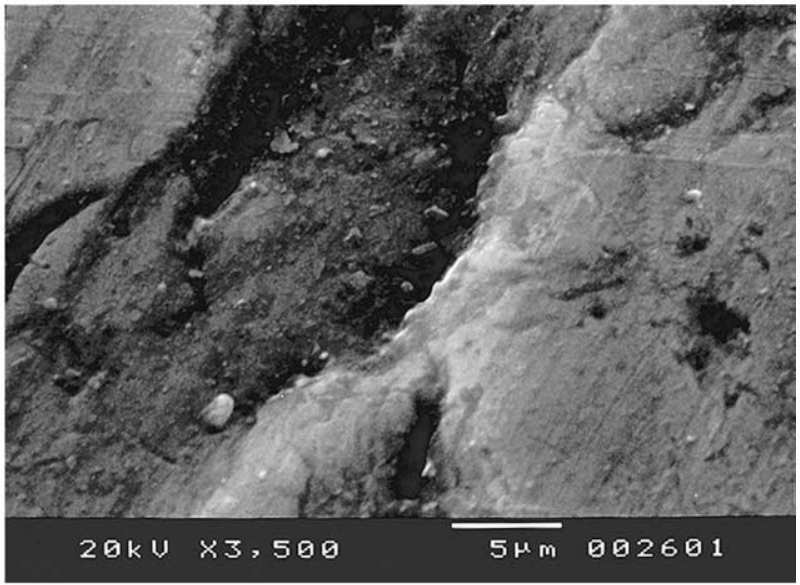

(d)

Fig. 3. SEM micrographs of (a) P1, $l=0.02 \mathrm{~mm}$, (b) $\mathrm{P} 2, l=0.06 \mathrm{~mm}$, (c) $\mathrm{P} 3, l=0.03 \mathrm{~mm}$ and (d) PANi, $l=0.05 \mathrm{~mm}$. $\times 3500$

aqueous solution, showing the effect of the matrix on the diffusing species. The magnitudes of these parameters $(P$ and $D$ ) are also similar to those observed for moderately hydrophilic cellulose derivatives [14] and are one order of magnitude lower than for $\mathrm{NaCl}$ in cellulose acetate [13]. This also suggests that the cellulose acetate structure is the main parameter controlling the diffusion. It is also interesting to observe that the variation of $P$ and $D$ with SDS concentration is similar to that reported earlier [29] in gas/ polymer systems and can be expected to be due to specific interactions between the diffusing species and polymer.

Previous studies on cellulose acetate/SDS systems have also suggested that aggregation, e.g. hemimicelle formation can occur in CA surface [30]. Fluorescence measurements using pyrene as a probe of CA membranes after equilibrium with SDS $10^{-2} \mathrm{M}$ have shown a decrease of the intensity ratio of the vibronic bands $\left(I_{1} / I_{3}\right)$ from 1.06 to 0.82 relative to $\mathrm{CA}$ /pyrene. This intensity ratio is a direct measure of polarity [31], and the decrease in the presence of SDS shows that the surface of CA is becoming more hydrophobic, in agreement with the idea of surface hemimicelle formation.
This surface modification can explain the decrease of the permeability coefficients with an increase of SDS concentration. It is now important to discuss the reason for the increase in the diffusion coefficient. Two main possibilities are considered, both involving increase in free volume within the membrane: (a) the SDS-CA interaction at polymer surface will decrease the amount of diffusing species inside polymeric matrix, and consequently increase the free volume available for diffusion; and (b) an increase in free volume resulting from changes in morphology of the CA membrane. In a previous manuscript [32] the effect of structure and water sorption on the water diffusion coefficients has been discussed. It has been reported that water solubility depends on membrane thickness. Considering the weight/weight water concentration for each cellulose acetate sample, the polymer density, $d_{\mathrm{p}}$, and Eq. (7) [33]

$\varphi_{\mathrm{p}}=\left(1+C_{\mathrm{w}} \frac{d_{\mathrm{p}}}{\rho_{0}}\right)^{-1}$

the polymer volume fraction can be calculated, assuming 


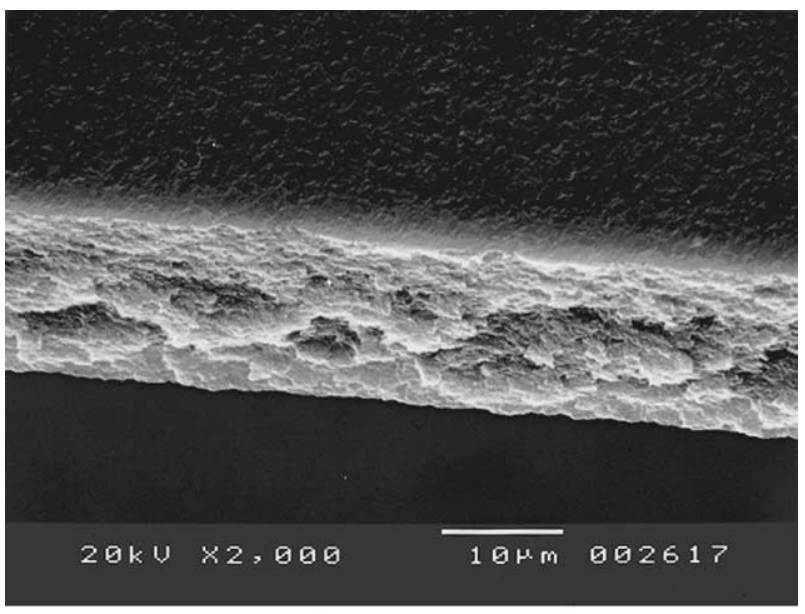

(a)

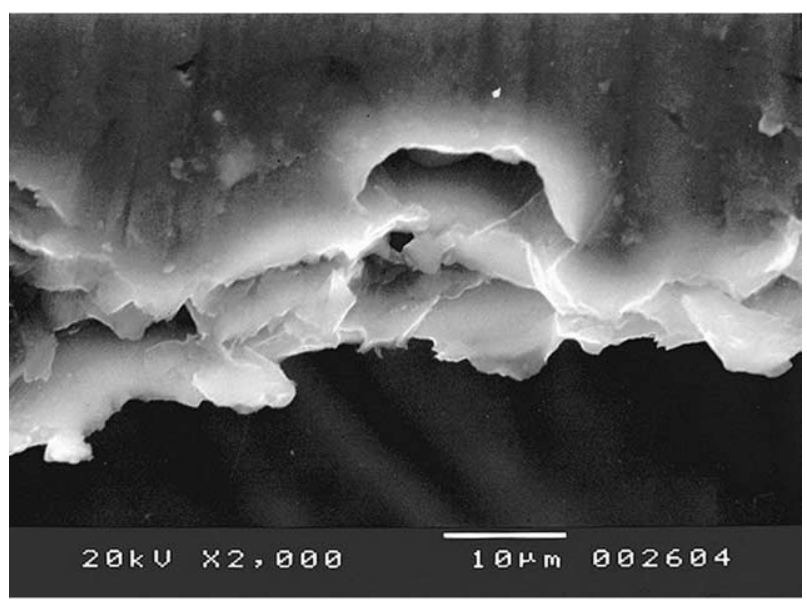

(b)

Fig. 4. SEM micrographs of the cross-section area of (a) $\mathrm{P} 3, l=0.030 \mathrm{~mm}$ and (b) PANi, $l=0.050 \mathrm{~mm}$. $\times 2000$.

that all sorbed water has the same density, $\rho_{0}$, as liquid water.

Fig. 7 shows the variation of $D$ with $\phi_{\mathrm{p}}$. There is a linear good fit of experimental values (correlation coefficient 0.995: $\left.D=3.91(0.12) \times 10^{-15}-4.30(0.20) \times 10^{-15} \phi_{\mathrm{p}}\right)$. Consequently, the major parameter affecting the diffusion process is suggested to be the free volume, under steadystate conditions.

Figs. 8 and 9 show the diffusion and permeability coefficients of SDS through membranes P2 and P3, respectively. The variation of $P$ and $D$ with SDS concentration in these polymers are very different from that obtained in CA membranes. The SDS diffusion coefficients are an order of magnitude higher than in CA, showing that the bulk polymer properties (polymer density) are important in the diffusing process.

From Fig. 8, two major points deserve to be discussed for membrane P2: (a) the variation of SDS diffusion coefficients with concentration, which change in a similar way to that for aqueous solution [34] and (b) the increase in permeability coefficients in the pre-micellar region, followed by a plateau at SDS concentrations above the cmc. Various factors may be involved in the influence of PANi on the transport properties. Although the increase of $P$ and decrease of $D$, in the pre-micellar region, can be explained by a concentration gradient, the effects on $P$ and $D$ above the cmc suggest that micelles can also have an important effect on the polymer properties. The mutual diffusion coefficients can be related to a frictional factor (which depends on the size of the diffusing molecules and viscosity) and an equilibrium thermodynamic factor for the change in chemical potential with concentration [35]. Therefore, the decrease in $D$ with the initial increase in surfactant concentration can be explained by a reduction in the thermodynamic factor (related to the variation of the activity coefficient with $c$ ), while the increase of $D$ with $c$ above the $\mathrm{cmc}$ can be explained by a decrease in the resistance coefficient, which is a measure of the friction acting on a solute as it moves through a solvent [36]. Such a decrease in the resistance coefficient on formation of aggregates/micelles may result from two effects, a decrease in the effective water free volume, and a low molar micelle concentration. Although the friction acting on a single micelle is much greater than that acting on a single surfactant unimer, the concentration of the former species is much lower, and on a per mole basis the transport in the micellar form is actually more efficient [37]. It is interesting to note that the decrease of $D$ in premicellar region is approximately $80 \%$, which is very similar to that found in aqueous solution (around 70\%). The sharp increase of $D$ in the post-micellar region can be interpreted in terms of both an increase of surface resistance to SDS sorption and some possible interaction with PANi. These effects will lead to a decrease of sorbed concentration inside polymeric matrix and a decrease of effective water free volume as pointed out above, thus increasing surfactant mobility inside the membrane. Although there is no direct evidence for these effects, support comes from results obtained with SDS/P3 systems.

In polymer P3, the transport of SDS shows a sharp decrease of $D$ (approximately two orders of magnitude) followed by a plateau above the $\mathrm{cmc}$, while a continuous decrease is observed in the permeability coefficient. Further, the magnitude of the diffusion coefficients is higher than in polymer P2. This is likely to be due both to a strong interaction between SDS and PANi, leaving only a low concentration of free unimer available to diffuse (to $0.1 \mathrm{mM}$ SDS the interaction is almost negligible and, as a consequence, a very high $D$ and $P$ ) and also to restrictions on the diffusion process by steric hindrance and/or a decrease of a water free volume fraction.

Strong interaction between SDS and PANi is indicated by changes in colour from blue to green of the membranes, and the modification in the visible absorption spectrum, where a clear shift in the maximum is observed (Fig. 10). At low surfactant concentrations only a very small shift is observed. At $10^{-4} \mathrm{M}$ SDS, $\Delta \lambda=13 \mathrm{~nm}$. However, at the 


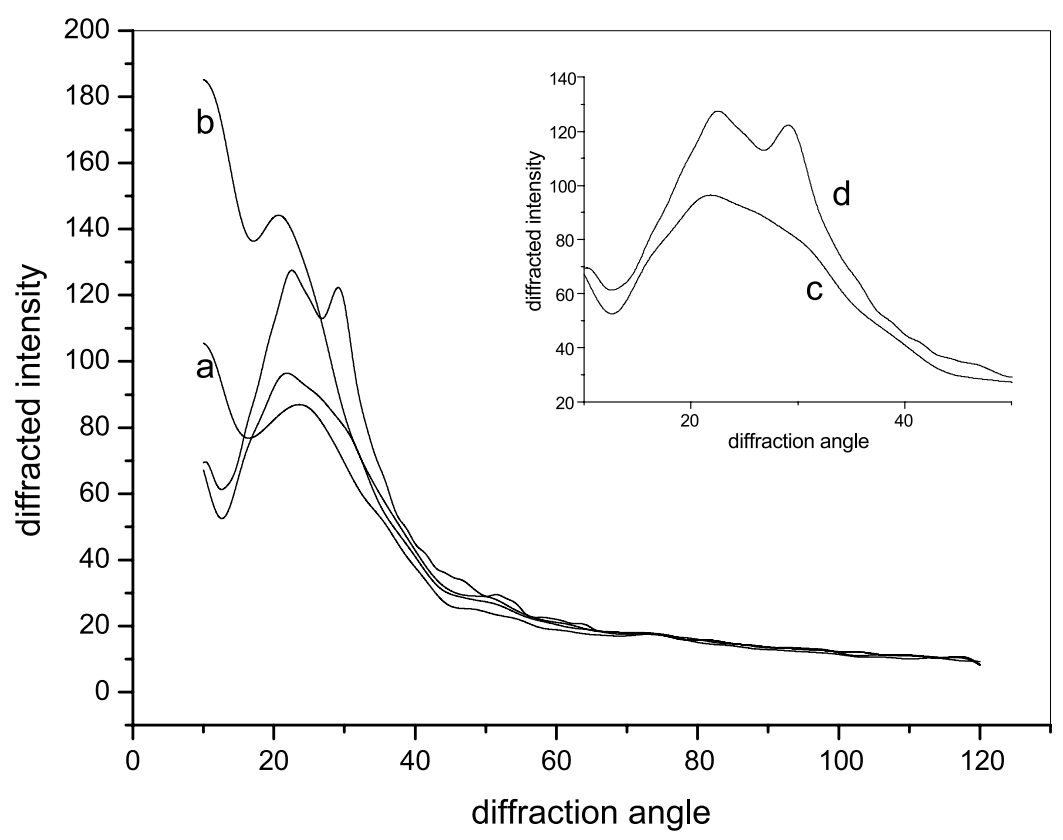

Fig. 5. X-ray diffraction patterns of (a) $\mathrm{P} 1, l=0.020 \mathrm{~mm}$; (b) $\mathrm{P} 2, l=0.060 \mathrm{~mm}$; (c) $\mathrm{P} 3, l=0.030 \mathrm{~mm}$, and (d) PANi, $l=0.050 \mathrm{~mm}$.

shift increases with concentration, and at $[\mathrm{SDS}]=10 \mathrm{mM}$, $\Delta \lambda=167 \mathrm{~nm}$. In the presence of the anionic surfactant, two different interaction mechanisms, between this and the conducting polymer can occur: (a) it acts through electrostatic interactions as a counter ion for conductingpolymer polycations, and (b) hydrophobic interactions lead to adsorption on the conducting polymer. These interactions have previously been studied by conductivity [38] in polymers synthesized directly in the presence of the surfactants. In the present case, it appears that the same interactions are involved between the polymer membrane and SDS, and are a direct consequence of SDS sorption.

To study the reversibility of the SDS-P3 interaction, samples of P3 were submitted to sorption/desorption cycles. Fig. 11 shows the effects of sorption and desorption of SDS by P3 as seen by UV-vis spectroscopy. Assuming that the concentration of SDS which interact with P3 is responsible for the shift in the maximum wavelength, $\Delta \lambda$ is a direct

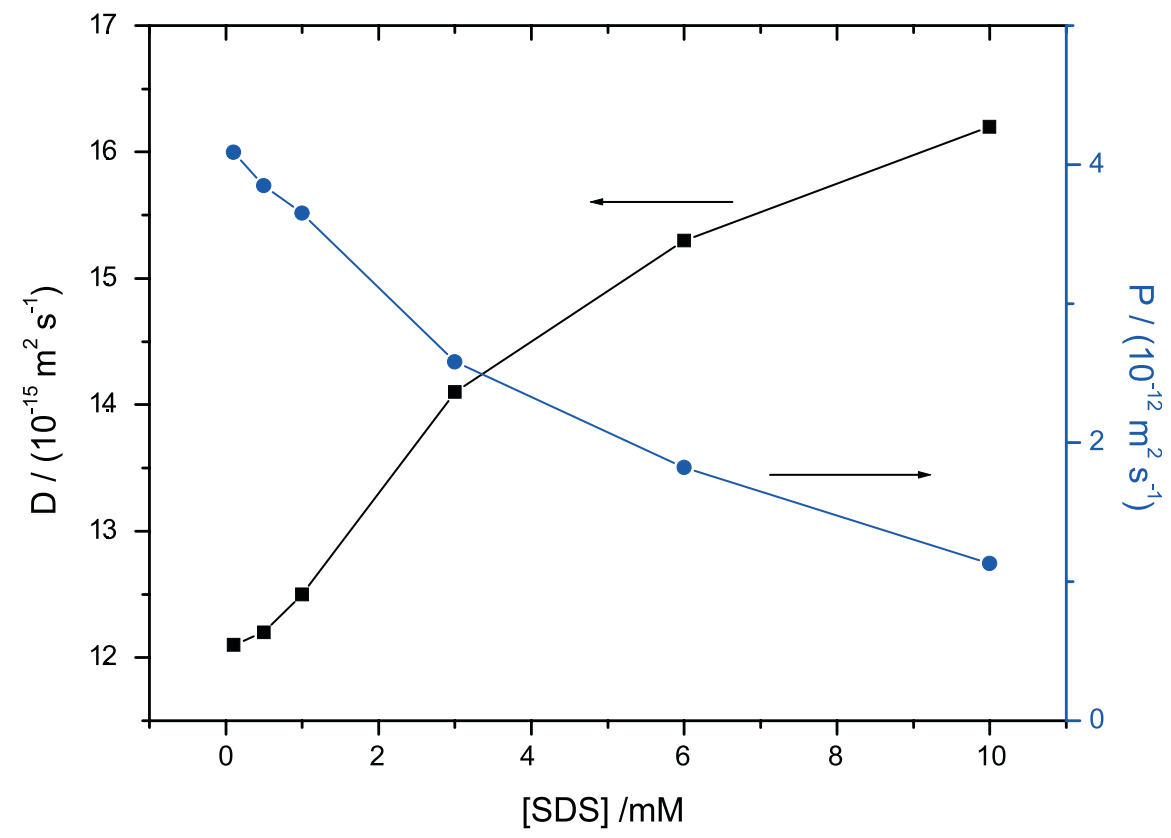

Fig. 6. Permeability, $P$, and diffusion, $D$, coefficients of SDS in cellulose acetate membranes, at $25^{\circ} \mathrm{C}$. The lines are just to guide the eyes. 


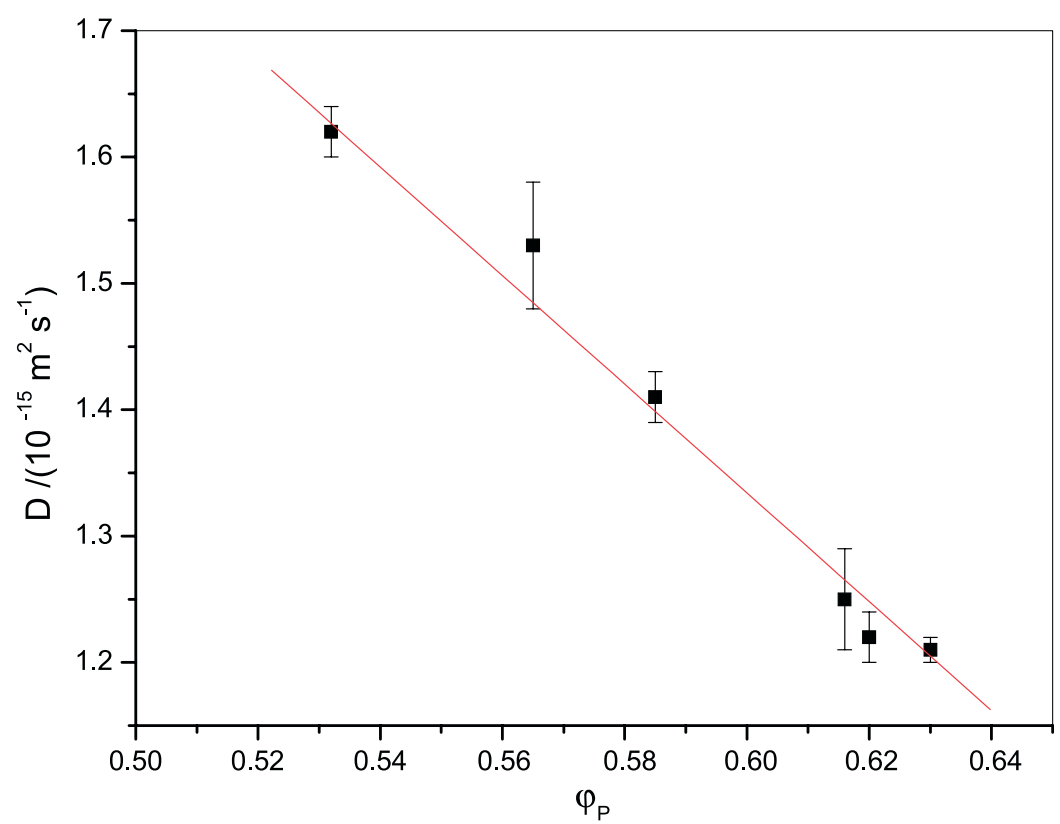

Fig. 7. Effect of the polymer volume fraction, $\phi_{\mathrm{p}}$, on the diffusion coefficients, $D$, of SDS in cellulose acetate membranes.

measure of SDS species linked to polymer structure. As we can observe from the shift, the amount of immobilized SDS, which leads to the formation of the green colour, is approximately one half of the total amount of SDS sorbed by the polymer. The observed interactions help explain the decrease in both permeation of SDS due to steric effects, as well as the decrease in SDS diffusion. The process is partially reversible, but the shift observed on desorption for $160 \mathrm{~h}$ indicates some SDS is still bound to the PANi.

\section{Conclusions}

The preparation of PANi-cellulose acetate derivatives is accompanied by alteration of the morphological properties of the polymer blends. Even the formation of dispersed PANi in a cellulose acetate matrix will change the polymeric properties of the supported material. Such alterations have been observed in the present study by SEM, DSC and X-ray diffraction. These alterations also change the water transport properties of these

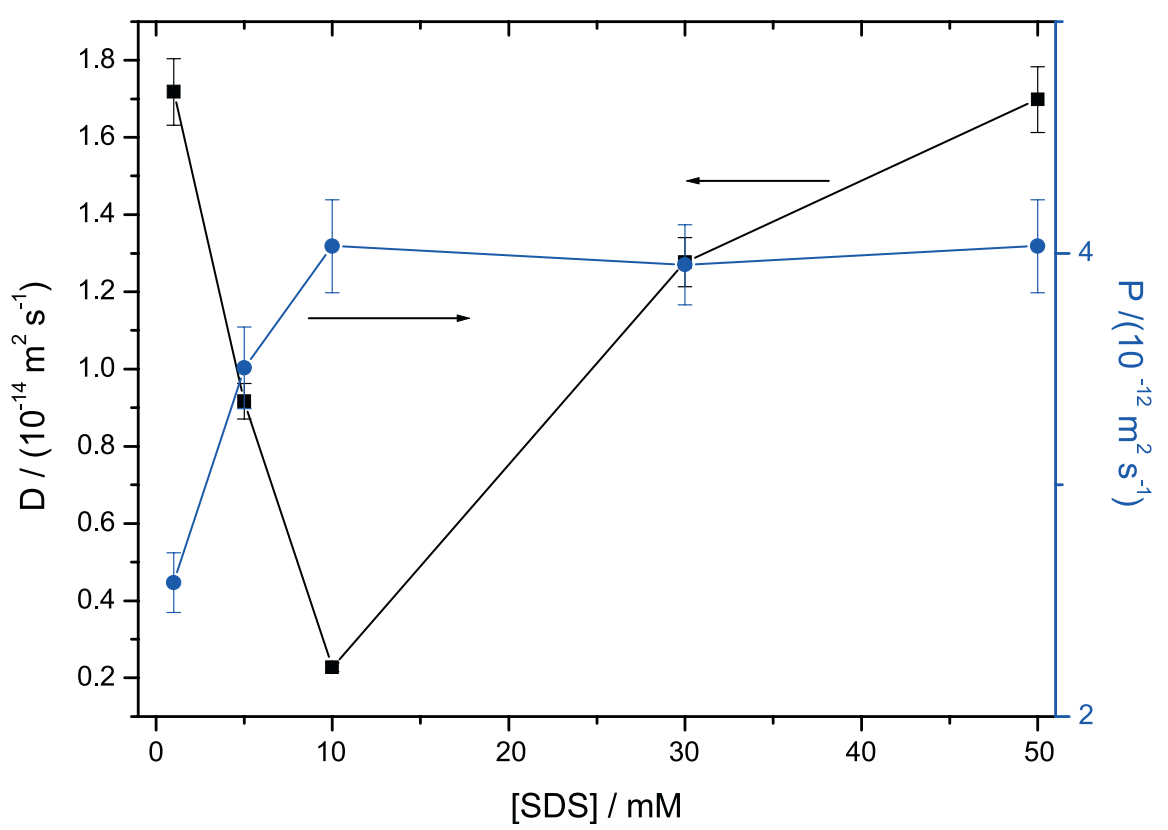

Fig. 8. Permeability, $P$, and diffusion, $D$, coefficients of SDS in polymer $\mathrm{P} 2$, at $25^{\circ} \mathrm{C}$. The lines are just to guide the eyes. 


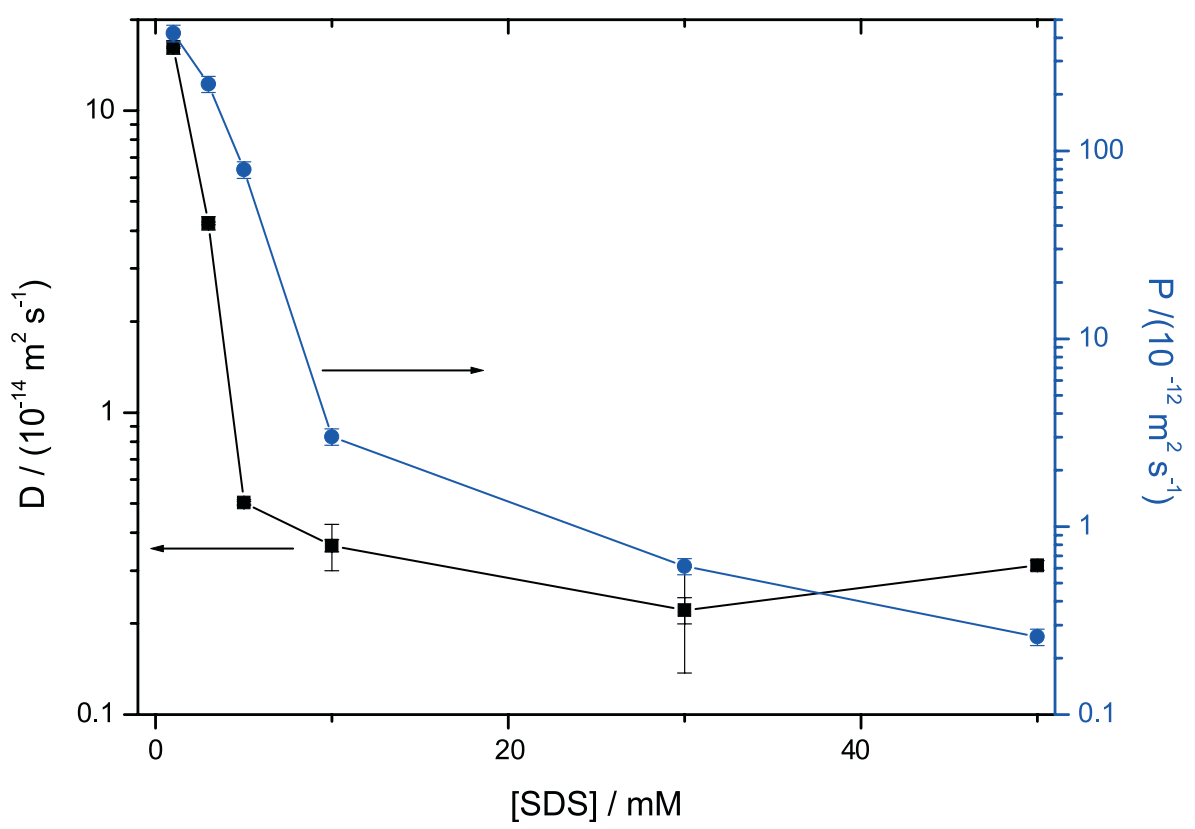

Fig. 9. Permeability, $P$, and diffusion, $D$, coefficients of SDS in polymer $\mathrm{P} 3$, at $25^{\circ} \mathrm{C}$. The lines are just to guide the eyes.

polymer blends. The water diffusion coefficients are mainly dependent on the polymer density, and no significant effect of the polymeric surface was found. The SDS transport depends on the kind of polymer, and the diffusion process is also micelle-dependent. Although the variation of $P$ and $D$ of SDS suggests some interaction between the surfactant and the polymer, it has been found that the main parameter influencing the diffusion is the polymer free volume fraction. However, with a blend, which had a fairly homogeneous distribution of PANi, significant modifications on the behaviour of $\mathrm{P}$ and $\mathrm{D}$ are observed, and the transport of SDS is accompanied by a partially irreversible interaction between this and the PANi. This interaction can be monitored by visible-spectroscopy, and may provide a good basis for use of this system as a SDS sensor. Work is in progress on this.

\section{Acknowledgements}

We thank, POCTI, FCT, FEDER and the Royal Society for financial support.

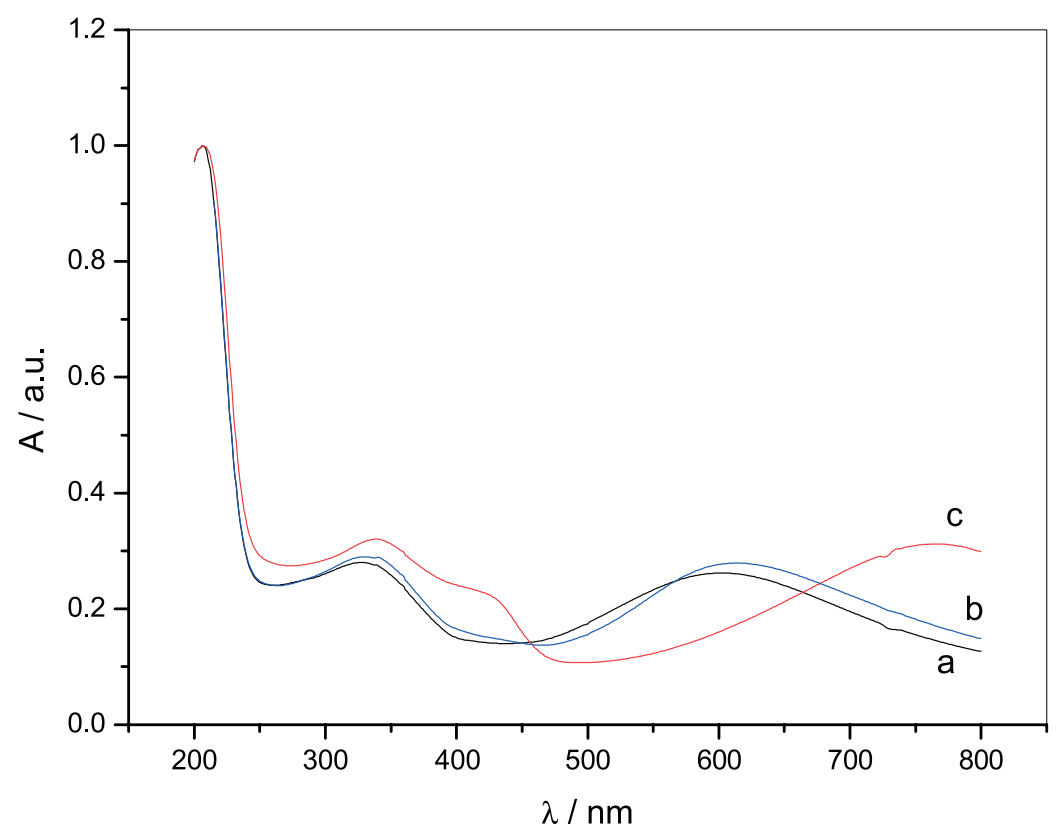

Fig. 10. UV-vis spectra of $\mathrm{P} 3$ in equilibrium with SDS at different concentrations: (a) $0 \mathrm{M}$; (b) $0.1 \mathrm{mM}$; (c) $10 \mathrm{mM}$. 


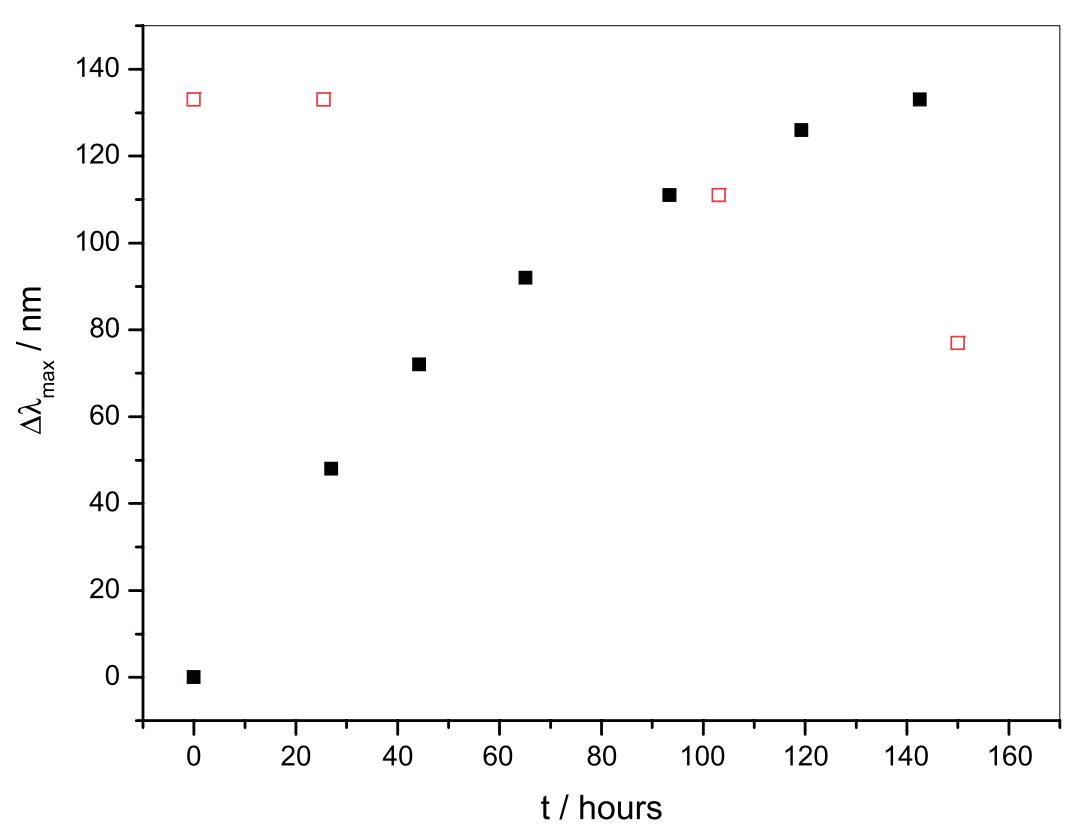

Fig. 11. Variation of the long wavelength absorption maximum in sorption (

/desorption ( $\square$ ) process in SDS/P3 system, as a function of time, at $25^{\circ} \mathrm{C}$.

\section{References}

[1] McDiarmid AG, Epstein AJ. Faraday Discuss Chem Soc 1989;88:317.

[2] Kaneko M, Nakamura H. J Chem Soc Chem Commun 1985;1441.

[3] DePaoli MA, Duek ER, Rodrigues MA. Synth Met 1991;41:973.

[4] Marques AP, Brett CMA, Burrows HD, Monkman AP, Retimal B. J Appl Polym Sci 2002;86:2182.

[5] Wolter A, Banka E, Genoud F, Pron A, Nechtschein M. Synth Met 1997;84:753.

[6] Planes J, Wolter A, Cheguettine Y, Pron A, Genoud F, Nechtschein M. Phys Rev B 1998;58:7774.

[7] Lindfors T, Sjoberg P, Bobacka J, Lewenstam A, Ivaska A. Anal Chim Acta 1999;385:163.

[8] Laska J, Wlodarczyk J, Zaborska W. J Mol Catal B: Enzym 1999;6: 549.

[9] Karg S, Scott JC, Salem JR, Angelopoulos M. Synth Met 1996;80: 111.

[10] Higgins RWT, Zaidi NA, Monkman AP. Adv Funct Mater 2001;11: 407.

[11] Adams PN, Laughlin PJ, Monkman AP, Kenright AM. Polymer 1996; 37:3411.

[12] Sabbah R, Xu-Wu A, Chickos JS, Leitão MLP, Roux MV, Torres LA. Thermochim Acta 1999;331:93.

[13] Lobo VMM, Murtinho DB, Gil MH, Garcia FP, Valente AJM. Int J Polym Mater 1996;32:221.

[14] Valente AJM, Polishchuk AYa, Lobo VMM, Burrows HD. Langmuir 2000;16:6475.

[15] Weinheimer RM, Evans DF, Cussler EL. J Colloid Interf Sci 1981;80: 357.

[16] Evans DF, Mukherjee S, Mitchell DJ, Ninham BH. J Colloid Interf Sci 1983;93:184.

[17] Cussler EL. Diffusion. Cambridge: Cambridge University Press; 1984. p. $164-5$.
[18] Jonsson B, Lindman B, Holmberg K, Kronberg B. Surfactant and polymers in aqueous solution. Chichester: Wiley; 1999.

[19] Louarn G, Lapkowski M, Quillard S, Pron A, Buisson JP, Lefrant S. J Phys Chem 1996;100:6998.

[20] Saravan S, Mathai CJ, Venhatachalan S. New J Phys 2004;6:64.

[21] Wang J, Yang YY, Zhang XZ, Zhu X, Chung TS, Moochhala S. Mater Sci Eng C 2002;20:93.

[22] Brandup J, Immergut EH, editors. Polymer handbook. 2nd ed. New York: Wiley; 1975. p. III-39.

[23] Conklin JA, Huang SC, Huang SM, Wen TL, Kaner RB. Macromolecules 1995;28:6522.

[24] Nunes T, Bastos M, Feio G, Gil MH, Burrows HD. Polymer 1995;36: 479.

[25] Li ZF, Ruckenstein E. J Colloid Interf Sci 2003;264:362.

[26] Planes J, Cheguettine Y, Samson Y. Synth Met 1999;101:789.

[27] Polishchuk AYa, Zaikov GE. Multicomponent transport in polymer systems for controlled release. Amsterdam: Gordon Breach Science Publication; 1997.

[28] Valente AJM, Burrows HD, Polishchuk AYa, Miguel MG, Lobo VMM. Eur Polym J 2004;40:109.

[29] Hamilton CJ, Murphy SM, Tighe BJ. Polymer 2000;41:3651.

[30] Childress AE, Deshmukh SS. Desalination 1998;118:167.

[31] Dong DC, Winnik MA. Can J Chem 1984;62:2560.

[32] Valente AJM, Polishchuk AYa, Burrows HD, Lobo VMM. Eur Polym J 2005;41:275.

[33] Naghash HJ, Okay O. J Appl Polym Sci 1996;60:971.

[34] Ribeiro ACF, Lobo VMM, Azevedo EFG, Miguel MG, Burrows HD. J Mol Liq 2003;102:285.

[35] Deng Z, Lu H, Leaist DG. J Chem Eng Data 1996;41:214.

[36] Tyrrell HJV, Harris KR. Diffusion in liquids. London: Butterworths; 1984. p. 52.

[37] Leaist DG. J Colloid Interf Sci 1986;55:230.

[38] Stejskal J, Omastova M, Federova S, Prokes J, Trchova M. Polymer 2003;44:1353. 